\title{
CORRELATIONS BETWEEN FIBER OUTPUT AND SOME ECONOMICALLY VALUABLE CHARACTERISTICS IN COTTON LINES IN DIFFERENT CULTIVATION REGIONS
}

\section{Juraev Sirojiddin Turdiqulovich ${ }^{1}$, Egamberdieva Saida Abdusamatovna ${ }^{2}$ Yakubjonova Nodirakhon Avazovna ${ }^{3}$}

\author{
${ }^{1}$ Associate Professor, Department of the Agricultural Crops Selection and Seed Breeding, \\ Tashkent State Agrarian University, Tashkent, Uzbekistan
}
${ }^{2}$ Doctor of Agricultural Sciences, Professor of the Department of the Agricultural Crops Selection and Seed Breeding, Tashkent State Agrarian University, Tashkent, Uzbekistan

${ }^{3}$ Assistant, Department of the Agricultural Crops Selection and Seed Breeding, Tashkent State Agrarian University, Tashkent, Uzbekistan

Article DOI: https://doi.org/10.36713/epra8808 DOI No: 10.36713/epra8808

\begin{abstract}
Phenotypic correlations were determined between fiber yield and some economic traits in ten lines of medium-fiber cotton Gossypium hirsutum grown in three different regions of Uzbekistan. It is noted that there is a direct relationship of average strength between the fiber yield and the length of the growing season.

KEYWORDS: cotton, phenotype, correlation, fiber yield, growing season length, fiber quality, productivity.
\end{abstract}

\section{INTRODUCTION}

It has been determined phenotypic correlations between fiber yield and some economic traits in ten lines of middle-fiber cotton G.hirsutum grown in three different regions of Uzbekistan. It is noted that there is a direct relationship of average strength between the fiber yield and the length of the growing season. Inverse relationship of varying degrees was observed between the fiber yield and the weight of 1000 seeds in the studied cotton lines, regardless of the growing region. Feedback of weak and medium strength was observed between the output and the length of the fiber. The specific breaking load of the fiber weakly correlated with the fiber yield, or there was no connection. In most cases, a direct relationship of medium strength was observed between the outlet and the microneir of the fiber. The fiber yield in the studied lines practically did not correlate with the weight of raw cotton per boll, productivity and yield of cotton. As a result of selection, it was possible to shift correlations in the required direction for a number of features such as yield and weight of 1000 seeds, yield and length of fiber, yield and microneir of fiber.

The study of correlations between traits provides information for conducting selection in one direction or another and purposefully carrying out breeding work for a complex of traits.

At the moment, a fairly large, but far from complete, material has been accumulated on the study of the correlations of various traits in cotton.

The aim of the researches. to study the relationship between the yield of fiber and the main economically valuable traits of cotton grown in three regions of Uzbekistan. 


\section{SJIF Impact Factor 2021: 8.013| ISI I.F.Value:1.241| Journal DOI: 10.36713/epra2016 ISSN: 2455-7838(Online) \\ EPRA International Journal of Research and Development (IJRD) \\ Volume: 6 | Issue: 10 | October 2021 \\ - Peer Reviewed Journal}

\section{MATERIALS AND METHODS}

Researches were carried out in 2018-2020. on the fields of the Institute of Breeding, Seed Production and Agricultural Technology of Cotton Growing (Tashkent region, Salar settlement), as well as branches of the Institute in Fergana region (Kuva) and Kashkadarya region (Kasbi), differing in soil and climatic conditions. The sowing of seeds was carried out at the optimum time. Sowing pattern $60 \mathrm{~cm} \times 20 \mathrm{~cm} \times 1$ plant.

We used 10 lines of cotton of the species Gossypium hirsutum L., obtained on the basis of introgressive forms with the participation of the wild species Gossypium trilobum Skovsted, as well as varieties of foreign selection from the collection of NIISSAVKh. The most productive individual selections of these lines were divided into three parts and their seeds were sown in three different ecological zones Tashkent,

Fergana and Kashkadarya regions of the republic. Studied the early ripening, the mass of raw cotton one box, the mass of 1000 pieces. seeds, fiber yield, length, specific breaking load, fiber microneir, as well as productivity and yield. Statistical processing of the data was carried out according to B.A. Dospokhov.

\section{RESULTS AND DISCUSSION}

As the data in the table show, for the studied lines in all the years of testing in different regions of cultivation between the fiber yield and the length of the growing season, a direct relationship of average strength was observed - the correlation coefficient was from 0.28 to 0.60. That is, with an increase in the length of the growing season, the yield of fiber, as a rule, also increased. In the overwhelming majority of cases, there was no correlation between the fiber yield and the weight of raw cotton of one boll, and only in the Fergana region in 2020 and in the Kashkadarya region in 2018 there were weak direct correlations $\mathrm{r}=0.29$ and $\mathrm{r}=0.23$, respectively.

An inverse relationship from a weak to a high degree from -0.02 to -0.54 was observed between the fiber yield and the weight of 1000 seeds in cotton lines, regardless of the growing region. It should be noted that in the third year of testing, the relationship between these characters was practically absent in the Tashkent and Fergana regions, that is, a high fiber yield was observed both in small-seeded forms and large-seeded ones.

The creation of cotton varieties that combine high yield and fiber quality has always been of interest to breeders [2]. The study of the relationship between these features contributes to a targeted search for forms with positive correlations.

The data in the table show that in the first two years of experiments, the lines showed weak and mediumstrength feedbacks between the output and the length of the fiber. The correlation coefficient varied from -0.05 in the Tashkent region in 2018 to -0.35 in the same place in 2019.In 2020, the tested lines showed a positive change in the correlation coefficient in all three regions: from 0.03 to 0.39 . This is apparently due to the influence of the selection of forms that combine high quality with high fiber yield.

The data in the table show that in the first two years of experiments, the lines showed weak and mediumstrength feedbacks between the output and the length of the fiber. The correlation coefficient varied from -0.05 in the Tashkent region in 2018 to -0.35 in the same place in 2019.In 2020, the tested lines showed a positive change in the correlation coefficient in all three regions: from 0.03 to 0.39 . This is apparently due to the influence of the selection of forms that combine high quality with high fiber yield.

In most cases, the specific breaking load of the fiber weakly correlated with the fiber yield, or there was no connection. And only in the first year of testing in the Tashkent region, a direct relationship of the average strength $r=0.35$ was noted between these features.

Microneir is an indicator that characterizes the fineness and maturity of cotton fiber. For I and II grades of cotton fiber, the acceptable range is $3.5-4.9$ microns / inch. Below 3.5, fiber is considered immature and has little cellulose. Above 4.9 - overripe, rough [3]. Therefore, the breeder should be interested in negative associations between microneir and some other trait.

As can be seen from the table in 2018 and 2019, that is, in the first two years of testing between the yield and microneir of the fiber, in most cases, there was a direct relationship of average strength, the correlation coefficient was from 0.30 to 0.57 . In Fergana and Kashkadarya regions, in different years, there was a strong direct relationship between these characters ( $\mathrm{r}=$ 0.83 and $r=0.71$, respectively). As in the case with the fiber length in the third year of testing, the correlation coefficient shifted, but only in a different, negative direction. In all three regions in 2020, weak feedbacks between these signs were noted (from -0.20 to -0.16).

Fiber yield did not practically correlate with productivity. In the third year of testing, in two cases in the Fergana and Kashkadarya regions, a weak direct relationship was noted $(r=0.33$ and $r=0.24$, respectively). 


\section{EPRA International Journal of Research and Development (IJRD)}

Table 1

Correlations in cotton lines between fiber yield and main economically valuable traits

\begin{tabular}{|c|c|c|c|c|c|c|c|c|c|c|}
\hline & 晜 & 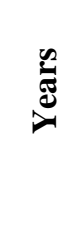 & 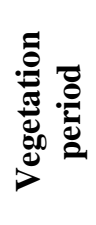 & $\begin{array}{l}\dot{\dot{\theta}} \\
\hat{z} \\
\stackrel{\Xi}{\Xi} \\
\overline{\bar{\Xi}} \\
\dot{0}\end{array}$ & 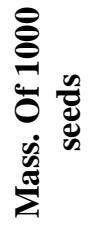 & 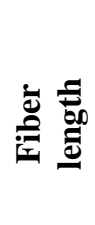 & 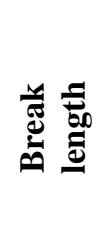 & & 苞 & $\stackrel{ }{\frac{\sigma}{\varrho}}$ \\
\hline \multirow{3}{*}{ 离 } & \multirow{3}{*}{ 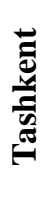 } & 2018 & 0.56 & 0.09 & -0.16 & -0.05 & 0.35 & 0.50 & 0.05 & -0.33 \\
\hline & & 2019 & 0.36 & -0.01 & -0.45 & -0.35 & 0.006 & 0.30 & 0.03 & -0.007 \\
\hline & & 2020 & 0.47 & 0.05 & -0.02 & 0.39 & -0.14 & -0.16 & 0.05 & -0.001 \\
\hline \multirow{3}{*}{ 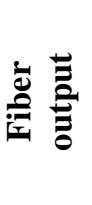 } & \multirow{3}{*}{ 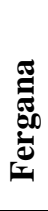 } & 2018 & 0.35 & 0.09 & -0.45 & -0.26 & 0.04 & 0.57 & -0.05 & -0.09 \\
\hline & & 2019 & 0.49 & -0.03 & -0.54 & -0.11 & 0.22 & 0.83 & -0.09 & -0.02 \\
\hline & & 2020 & 0.49 & 0.29 & -0.02 & 0.03 & -0.01 & -0.20 & 0.33 & 0.49 \\
\hline \multirow{3}{*}{ 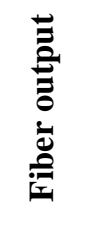 } & \multirow{3}{*}{ 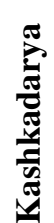 } & 2018 & 0.60 & 0.23 & -0.32 & -0.30 & 0.20 & 0.71 & -0.02 & -0.47 \\
\hline & & 2019 & 0.28 & -0.03 & -0.21 & -0.34 & 0.10 & 0.46 & -0.09 & 0.17 \\
\hline & & 2020 & 0.40 & -0.005 & -0.20 & 0.06 & 0.07 & -0.20 & 0.24 & 0.04 \\
\hline
\end{tabular}

Over the years of testing, in the overwhelming majority of cases, the yield of the lines did not depend on the fiber yield. That is, both high and low water lines could be productive. In 2018, in the Tashkent and Kashkadarya regions, an inverse relationship of average strength $r=-0.33$ and $r=-0.47$ was noted between fiber yield and yield, respectively. And in the Fergana region in 2020, these signs positively correlated with each other, $r=0.49$.

\section{CONCLUSION}

Thus, the analysis of correlations between the yield and some other economically valuable traits according to the data of three-year tests of cotton lines of various genetic origin showed that there is a direct relationship of average strength between the fiber yield and the length of the growing season. That is, an increase in the length of the growing season, as a rule, also increases the yield of fiber. In the overwhelming majority of cases, there was no correlation between the fiber yield and the weight of raw cotton of one boll.

An inverse relationship was observed between the fiber yield and the weight of 1000 seeds in the studied cotton lines, regardless of the growing region. Feedback of weak and medium strength was observed between the exit and the length of the fiber. The specific breaking load of the fiber weakly correlated with the fiber yield, or there was no connection. In most cases, a direct relationship of medium strength was observed between the outlet and the microneur of the fiber. Fiber yield practically did not correlate with the productivity and yield of cotton.

It should be noted that for a number of features such as output and weight of 1000 pieces. seeds, fiber yield and length, fiber yield and microneir, as a result of selection, it was possible to shift correlations in the required direction.

\section{REFERENCES}

1. Dospekhov B.A. (1979). Field experiment technique. Moscow, "Kolos", $416 \mathrm{p}$.

2. Simongulyan V.A. (1991). Genetics of quantitative traits of cotton. Tashkent, "FAN", $124 \mathrm{p}$

3. Ustyugun V.E., Maksudov I.T., Urunov N.D. (1991). Fiber of cotton. Technical condition. Tashkent, "SIFAT", $31 \mathrm{p}$. 